\title{
RAPID RECOVERY OF PINEAL FUNCTION AFTER PARTIAL DENERVATION: A POSSIBLE ROLE FOR HETERONEURONAL UPTAKE OF TRANSMITTER IN MODULATING SYNAPTIC EFFICACY ${ }^{1}$
}

\author{
R. E. ZIGMOND, ${ }^{2}$ C. BALDWIN, AND C. W. BOWERS ${ }^{3}$
}

Department of Pharmacology, Harvard Medical School, Boston, Massachusetts 02115

Received February 21, 1984; Revised May 17, 1984; Accepted June 29, 1984

\begin{abstract}
The pineal gland is innervated by sympathetic neurons whose cell bodies are located in the two superior cervical ganglia and whose axons reach the gland via the two internal carotid nerves (ICNs). Bilateral decentralization of the superior cervical ganglia, produced by lesioning both cervical sympathetic trunks (CSTs), abolishes the circadian rhythm in the activity of the pineal enzyme serotonin $N$-acetyltransferase (NAT). We have examined the effects on NAT activity of unilaterally cutting the ICN or the CST. During the first night after either operation, nocturnal NAT activity was reduced by $75 \%$ compared to controls. However, during the second night after unilaterally cutting the ICN, NAT activity was restored to control values, and normal enzyme activity was seen in these lesioned animals for up to 1 month after this operation. On the other hand, following unilateral decentralization of one superior cervical ganglion, enzyme activity was reduced for at least 5 months. The high enzyme activity in animals with one ICN cut was abolished by cutting the contralateral CST, indicating that the recovery of NAT activity depended on the remaining intact sympathetic neurons. Electrical stimulation of the intact ICN during the daytime in animals in which the contralateral ICN was cut produced an increase in pineal NAT activity which was greater than the increase seen when similar stimulation was performed in sham-operated animals or in animals in which the contralateral superior cervical ganglion had been decentralized. The time course of the recovery of nocturnal NAT activity after unilateral denervation of the pineal gland was similar to the time course of the decrease in norepinephrine uptake sites in the gland. No change in norepinephrine uptake was seen after cutting one CST. The NAT activity in animals in which one CST was cut could be restored to normal by either of two procedures: administration of desmethylimipramine, a norepinephrine uptake blocker, or a second operation in which the ipsilateral ICN was cut.

We propose that these results can be explained by a mechanism involving "heteroneuronal uptake" of neurally released norepinephrine (i.e., uptake of transmitter by a neuron other than the neuron from which the transmitter was released). It is proposed that the uptake of norepinephrine by electrophysiologically silent neurons on the lesioned side accounts for the inhibition of pineal function during the first night after cutting one ICN and at all times after cutting one CST. The return of NAT activity to normal in the unilaterally denervated pineal glands is attributed to the loss of the norepinephrine uptake capacity of the degenerating nerve terminals. This hypothesis may also be relevant to certain instances of recovery of function or loss of function after neural damage in the central nervous system and suggests a novel mechanism for the modulation of synaptic efficacy in intact tissues.
\end{abstract}

To what extent an organism is able to recover normal function following neural damage is a question of considerable scientific and clinical interest. The sympathetic innervation of the rat pineal gland has several attractive features as an experimental system for studies of this problem. First of all, the

\footnotetext{
${ }^{1}$ This work was supported by United States Public Health Service Research Grant NS17512. R. E. Z. was supported by National Institute of Mental Health Research Scientist Development Award MH00162, and C. W. B. was supported by National Institutes of Health Postdoctoral Training Grant NS07009.

${ }^{2}$ To whom correspondence should be addressed.

${ }^{3}$ Present address: Department of Physiology, University of California Medical School, San Francisco, CA 94143.
}

pineal gland is a midline structure innervated by sympathetic neurons from the two cervical sympathetic chains (Kappers, 1960; Owman, 1964; Wurtman et al., 1968; Moore, 1978). The cell bodies of these neurons are located exclusively in the two superior cervical ganglia (Bowers et al., 1984b), and their axons reach the pineal gland via the two internal carotid nerves (ICNs) (Zigmond et al., 1981; Bowers and Zigmond, 1982; Bowers et al., 1984a). Anatomical, biochemical, and physiological evidence indicates that the two sympathetic chains innervate the pineal gland to the same extent (Zigmond et al., 1981; Bowers and Zigmond, 1982; King et al., 1983; Bowers et al., 1984b). Thus, it is possible to lesion the sympathetic input to the pineal gland in a reproducible manner either totally or partially (i.e., by $50 \%$ ).

This pathway has a second advantage for studies on neural 
plasticity in that sympathetic activity produces an easily quantifiable transsynaptic effect in the pineal gland, namely, an elevation of the enzyme serotonin $N$-acetyltransferase (NAT; arylamine $N$-acetyltransferase, EC 2.3.1.5) (Klein et al., 1971; Volkman and Heller, 1971; Bowers and Zigmond, 1980, 1982). This enzyme shows a large (40- to 100 -fold) circadian rhythm in its activity with peak activity occurring during the nighttime. The nighttime rise in NAT activity can be blocked by bilateral superior cervical ganglionectomy (Klein et al., 1971), decentralization of the two ganglia (Klein et al., 1971), cutting of the two ICNs (Zigmond et al., 1981), or injection of the $\beta$ adrenergic antagonist propranolol (Deguchi and Axelrod, $1972 \mathrm{~b}$ ). Furthermore, the nighttime rise in NAT activity can be mimicked by electrical stimulation of the cervical sympathetic trunks (CSTs) (Bowers and Zigmond, 1982) or by systemic injection of the $\beta$-adrenergic agonist isoproterenol (Deguchi and Axelrod, 1972b). The magnitude of the increase in enzyme activity depends on the frequency, pattern, and duration of nerve stimulation (Bowers and Zigmond, 1982) or on the dose of isoproterenol administered (Deguchi and Axelrod, 1973a). Although, in animals exposed to certain "stressors," pineal NAT activity can be influenced by circulating catecholamines originating from the adrenal medulla (Lynch et al. 1973, 1977; Parfitt and Klein, 1976), under normal conditions the activity of this enzyme appears to reflect the extent of sympathetic neuronal stimulation of the gland.

We have used the sympathetic innervation of the pineal gland to study recovery of function after subtotal neural damage. Following unilateral superior cervical ganglionectomy or after cutting one ICN, the nocturnal activity of NAT was found to be considerably reduced. However, within $32 \mathrm{hr}$, enzyme activity had recovered to normal values (Zigmond et al., 1981). In contrast, following unilateral decentralization of the superior cervical ganglion, the same initial decrease in NAT activity occurred, but there was no rapid recovery of enzyme activity (Zigmond et al., 1981). In the current paper we explore the mechanisms behind these phenomena and present a model to account for our findings. The model, which may be applicable to a variety of peripheral and central neural systems, involves the proposal that heteroneuronal uptake (i.e., uptake of transmitter by a neuron other than the neuron which released the transmitter) can modulate synaptic efficacy.

\section{Materials and Methods}

Male Sprague-Dawley rats (100 to $125 \mathrm{gm}$ at the time of shipment) were used in all experiments. Unoperated animals were purchased from Charles River Breeding Laboratories (Wilmington, MA), and adrenalectomized and adrenal demedullated animals were purchased from Zivic Miller (Allison Park, PA). The adrenalectomized animals were given access to both salt water $(0.9 \% \mathrm{NaCl})$ and normal tap water and were injected subcutaneously with desoxycorticosterone $(10 \mathrm{mg} / \mathrm{kg})$ for 2 to 3 days before the second operation (see below). All animals were housed in individual plastic cages under controlled lighting (12-hr light:12-hr darkness) with ad libitum access to Purina Rat Chow and water for at least 10 days before an experiment. Except where noted in the figure legends, all surgical procedures were done during the last $2 \mathrm{hr}$ before the beginning of the dark period. Animals were anesthetized with chloral hydrate $(380 \mathrm{mg} / \mathrm{kg}$, i.p., or $640 \mathrm{mg} / \mathrm{kg}$, s.c.; Sigma Chemical Co., St. Louis, MO). The ICN was cut near its entry into the carotid canal and again near the superior cervical ganglion, removing a small piece of the nerve trunk (Fig. 1). The CST was cut a few millimeters before its entry into the superior cervical ganglion and again more caudally (Fig. 1). In experiments with long survival times (i.e., 1 month or longer), a large piece of the trunk, about $5 \mathrm{~mm}$ long, was removed. These operations were performed either unilaterally or bilaterally. Pineal glands in animals whose ICNs were cut are referred to below as "denervated" glands, while pineal glands in animals whose CSTs were cut are referred to as "decentralized" glands. "Sham-operated" animals were included in all experiments. These animals were anesthetized and had their appropriate nerve(s) exposed but not cut. In all experiments,

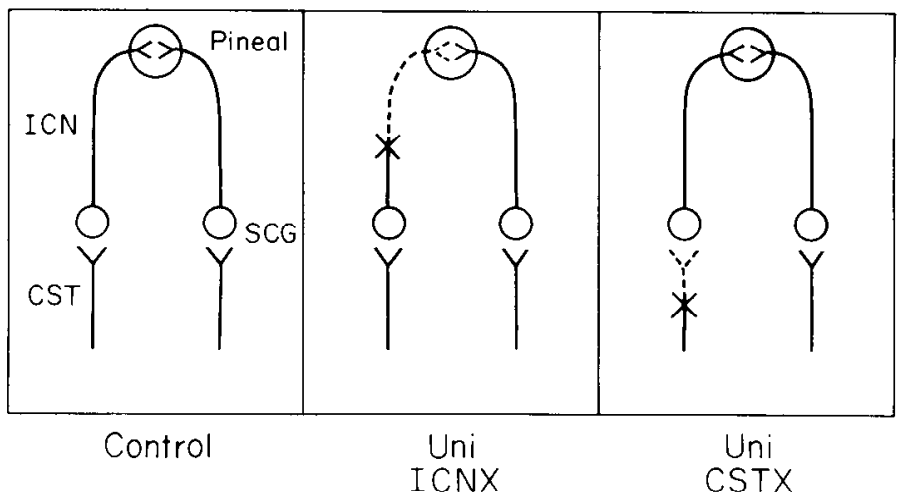

Figure 1. Diagram showing the sympathetic innervation of the normal pineal gland (left), and the location of the lesions made to unilaterally denervate (center) and unilaterally decentralize (right) the gland. $S C G$, superior cervical ganglion. The dashed lines denote anterograde degeneration resulting from the lesions. This diagram is reproduced from Zigmond et al. (1981).

except the stimulation experiment described below, animals were killed by decapitation under a dim red light (Kodak Safelight filter, 1 A, 15W bulb) 7 to $9 \mathrm{hr}$ into their dark cycle, and their pineal glands were quickly removed. When NAT activity was to be measured, the glands were immediately frozen on dry ice and stored at $-80^{\circ} \mathrm{C}$ until they were assayed. NAT activity was measured by a modification of a radiochemical assay developed by Deguchi and Axelrod (1972a) in which the rate of formation of $\left[{ }^{14} \mathrm{C}\right]-\mathrm{N}$-acetyltryptamine from $\left[{ }^{14} \mathrm{C}\right]$ acetyl-CoA (New England Nuclear Corp., Boston, MA) and tryptamine was measured (see Bowers and Zigmond, 1980, for details). The protein content of the pineal gland was assayed by the method of Lowry et al. (1951), using bovine serum albumin as the standard. NAT activity is expressed as picomoles of acetylated product formed per $20 \mathrm{~min}$ per microgram of protein \pm SEM or as a percentage of the activity in sham-operated controls. Tyrosine hydroxylase activity was measured in the adrenal glands of sham-operated and adrenal demedullated animals by determining the rate of formation of $\left[{ }^{3} \mathrm{H}\right]$ dopa from $\left[{ }^{3} \mathrm{H}\right]$ tyrosine. The method originally developed by Nagatsu et al. (1964) was used with modifications as described by Zigmond and Chalazonitis (1979), except that the mercaptoethanol concentration was lowered to $40 \mathrm{mM}$, catalase $\left(10^{5}\right.$ units $\left./ \mathrm{ml}\right)$ was added, 6 -methyltetrahydropterin $(3.2 \mathrm{mM})$ was used as the cofactor, and the reaction was run for $6 \mathrm{~min}$.

When pineal glands were assayed for both NAT activity and norepinephrine content, they were homogenized in $100 \mu \mathrm{l}$ of $0.1 \mathrm{M}$ sodium phosphate buffer, $\mathrm{pH} 6.8$, and $40-\mu \mathrm{l}$ aliquots were taken for each assay. Forty microliters of a solution containing $0.8 \mu \mathrm{M}$ epinephrine (as an internal standard), $0.3 \mathrm{M}$ trichloroacetic acid, and $0.2 \mathrm{mM}$ EDTA were immediately added to each sample that was to be assayed for its norepinephrine content, and the samples were frozen overnight at $-20^{\circ} \mathrm{C}$. After thawing, $1 \mathrm{ml}$ of $0.5 \mathrm{M}$ Tris, $\mathrm{pH} 8.6$, and approximately $10 \mathrm{mg}$ of acid-washed $\mathrm{Al}_{2} \mathrm{O}_{3}$ were added. The samples were mixed and centrifuged, and the pellets were washed three times with $5 \mathrm{~mm}$ Tris, $\mathrm{pH} 8.6$, containing $1 \mathrm{~mm} \mathrm{NaHSO}$. The catecholamines were then eluted from the alumina with $0.1 \mathrm{M} \mathrm{HCl}$ (Keller et al., 1976). Norepinephrine content was determined using high pressure liquid chromatography with electrochemical detection. The mobile phase contained $100 \mathrm{mM} \mathrm{H} \mathrm{PO}_{4}$ (pH 2.6), $0.1 \mathrm{mM}$ EDTA, 7\% methanol, and $0.2 \mathrm{~mm}$ octylsodium sulfate (Erny et al., 1981).

$\left[{ }^{3} \mathrm{H}\right]$ Norepinephrine uptake was measured in whole pineal glands in vitro by a modification of the method reported by Holz et al. (1974), as previously described (Bowers et al., 1984a). Pineal glands were preincubated with supplemented $\mathrm{BGJ}_{\mathrm{b}}$ medium (Grand Island Biological Co., Grand Island, NY) and were then incubated for 15 min with 1 to $5 \times$ $10^{-7} \mathrm{M}\left[{ }^{3} \mathrm{H}\right]$-l-norepinephrine (specific activity, $\sim 3 \mathrm{Ci} / \mathrm{mmol}$, New England Nuclear) and $12.5 \mu \mathrm{M}$ nialamide (Sigma). When desmethylimipramine was used, it was added to both the preincubation and incubation media. (Desmethylimipramine hydrochloride was a gift from USV Pharmaceutical Corp., Tuckahoe, NY.) After washing the glands, the total radioactivity retained by the glands was determined by sonicating them in $0.3 \mathrm{ml}$ of distilled water and measuring the tritium content in a liquid scintillation counter.

Certain animals were injected with desmethylimipramine intraperi- 
toneally, $7 \mathrm{hr}(20 \mathrm{mg} / \mathrm{kg})$ and $2 \mathrm{hr}(10 \mathrm{mg} / \mathrm{kg})$ before pineal glands were removed for determination of NAT activity. The first injection was made at the end of the light cycle and the second was made $5 \mathrm{hr}$ into the dark cycle. A control experiment was performed to determine the effectiveness of this regimen of drug administration in blocking norepinephrine uptake. Animals were injected with desmethylimipramine as above or with the saline vehicle alone. Two hours after the second dose, they were injected intravenously, via a jugular catheter, with approximately $0.5 \mathrm{nmol}$ of $\left[{ }^{3} \mathrm{H}\right]$ norepinephrine (specific activity, $47.7 \mathrm{Ci} / \mathrm{mmol}$; New England Nuclear). Ten minutes later, the tritium content of the pineal gland was measured as described in the previous paragraph.

The effects of electrical stimulation of the ICN were examined in animals after denervation or decentralization of the pineal gland. Animals were removed from the animal room no sooner than $4 \mathrm{hr}$ into their light cycle and anesthetized with chloral hydrate, and their ICNs were exposed. The ICN was stimulated unilaterally for $3 \mathrm{hr}$ at $5 \mathrm{~Hz}$ in animals that (1)had been sham-operated, (2) had their contralateral ICN cut, or (3) had their contralateral CST cut $32 \mathrm{hr}$ earlier. In one group of sham-operated animals the ICN was stimulated bilaterally, and one group of animals whose ICN had been cut unilaterally was kept under anesthesia for $3 \mathrm{hr}$ but the nerves were not stimulated. Further details of the stimulation procedure can be found in Bowers and Zigmond (1982).

The significance of differences between groups was analyzed by the Student's $t$ test for two means (two-tailed).

\section{Results}

\section{Characterization of the recovery phenomenon}

NAT activity was measured at various times after unilateral denervation and unilateral decentralization of the pineal gland to determine whether the difference in enzyme activity between these two groups, which we previously reported (Zigmond et al., 1981), represented (1) a temporary elevation of enzyme activity in denervated glands, (2) a slower time course of recovery in decentralized glands, or (3) a long-lasting difference between the two groups. Nine hours after unilateral denervation, NAT activity was decreased to $25 \%$ of control values. However, $32 \mathrm{hr}$ after the operation, enzyme activity had recovered to normal, and normal values were found in animals $80 \mathrm{hr}$ and 1 month after the operation (Fig. 2). Unilateral decentralization also produced about a $75 \%$ decrease in enzyme activity $9 \mathrm{hr}$ after the operation; however, this low level of enzyme activity was maintained for at least 5 months (Fig. 2).

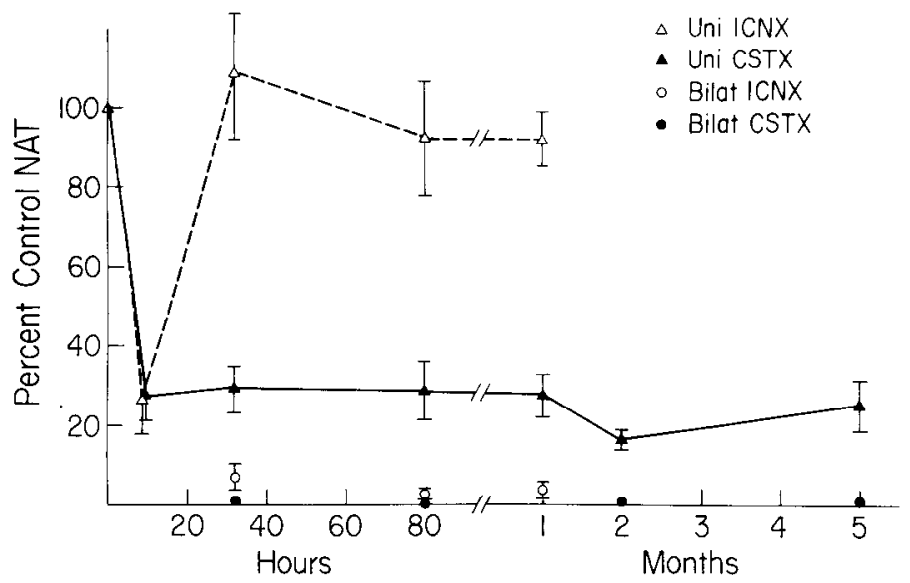

Time After Lesion

Figure 2. Time course of changes in nocturnal NAT activity following denervation or decentralization. The pineal gland was denervated by cutting one or both ICNs (Uni ICNX or Bilat ICNX, respectively), or was decentralized by cutting one or both CSTs (Uni CSTX or Bilat CSTX). Nocturnal NAT activity was measured 7 to $8 \mathrm{hr}$ into the dark cycle at various times after the operation. Each data point represents the mean \pm SEM of at least seven pineal glands. Some of the data at 9, 32, and $80 \mathrm{hr}$ after the lesions were taken from Zigmond et al. (1981).
The recovery of NAT activity after unilateral denervation could result solely from stimulation via neurons in the contralateral sympathetic chain, or it could result from increased stimulation via circulating catecholamines. One source of circulating catecholamines that has been shown to affect pineal NAT activity is the adrenal gland (Lynch et al., 1977). To examine the importance of adrenal catecholamines for the recovery process, animals were adrenalectomized or adrenal demedullated prior to cutting the ICN unilaterally. Neither operation significantly affected the NAT activity in shamoperated animals or in animals measured $32 \mathrm{hr}$ after unilateral denervation (Table I). To determine whether the NAT activity in unilaterally denervated pineal glands was entirely dependent on stimulation via neurons in the contralateral superior cervical ganglion, animals whose ICN had been cut unilaterally had their contralateral CST cut. Thirty two hours after the second operation, NAT was decreased by $99 \%$ in these doubly lesioned animals (Fig. 3).

One possible mechanism which could underlie the recovery of pineal function is that the sympathetic neurons contralateral to the lesion might increase their firing rates via some feedback mechanism. Alternatively, the recovery might reflect (at least in part) an increase in the response of the pineal gland to the same frequency of sympathetic nerve activity. To examine these possibilities, the sympathetic input to the pineal gland was stimulated electrically in control animals and in animals after unilateral denervation and unilateral decentralization of the gland. The nerves were stimulated during the daytime for $3 \mathrm{hr}$ at $5 \mathrm{~Hz}$. This frequency was chosen because it produces a large but submaximal increase in NAT activity (J. R. Lingappa and R. E. Zigmond, unpublished observations) and, therefore, it was considered to be a more sensitive test of synaptic efficacy than a supermaximal frequency. Daytime values for NAT activity in all three groups have previously been shown to be very low (i.e., $<5 \mathrm{pmol} / \mu \mathrm{g}$ of protein $/ 20 \mathrm{~min}$ ) (Zigmond et al., 1981; Bowers et al., 1984a). Bilateral stimulation of the ICN produced a large increase in NAT activity, bringing the activity of this enzyme to about $65 \%$ of that seen in unoperated animals during the middle of their dark cycle (Fig. 4). Unilateral stimulation in sham-operated animals produced a much smaller effect ( $p$ $<0.001$ ), as did unilateral stimulation in animals whose pineal glands had been unilaterally decentralized previously $(p<$ 0.01 ). However, unilateral stimulation produced a high level of

\section{TABLE I}

Lack of effect of adrenalectomy and adrenal demedullation on the recovery in NAT activity following unilateral denervation

Animals that had been sham-operated (Sham), adrenalectomized (ADX), or adrenal demedullated (MEDX) 2 weeks earlier were either sham-operated (Sham) or had their ICN cut unilaterally (Uni ICNX). Thirty-two hours later, nocturnal NAT activity was measured. The data represent the means \pm SFM. Tyrosine hydroxylase activity was measured in the adrenal glands of sham-operated and adrenal demedullated animals. Enzyme activity in the latter group was less than $1 \%$ of that found in the former, thus suggesting that the demedullation was successful.

\begin{tabular}{|c|c|c|}
\hline $\begin{array}{c}\text { Experiment } \\
\text { No. }\end{array}$ & Operation & NAT Activity \\
\hline & & $\mathrm{pmol} / \mu \mathrm{g}$ protein $/ 20 \mathrm{~min}$ \\
\hline 1 & $\begin{array}{l}\text { Sham/Sham } \\
\text { ADX/Sham } \\
\text { ADX/Uni ICNX }\end{array}$ & $\begin{array}{l}49.0 \pm 5.0(10)^{a} \\
50.9 \pm 4.9(5) \\
37.3 \pm 7.3(5)\end{array}$ \\
\hline 2 & $\begin{array}{l}\text { Sham/Sham } \\
\text { MEDX/Sham } \\
\text { MEDX/Uni ICNX }\end{array}$ & $\begin{array}{l}46.5 \pm 3.4(9) \\
43.4 \pm 4.7(8) \\
40.3 \pm 3.0(9)\end{array}$ \\
\hline
\end{tabular}

${ }^{a}$ Numbers in parentheses, number of pineal glands included in each group. 


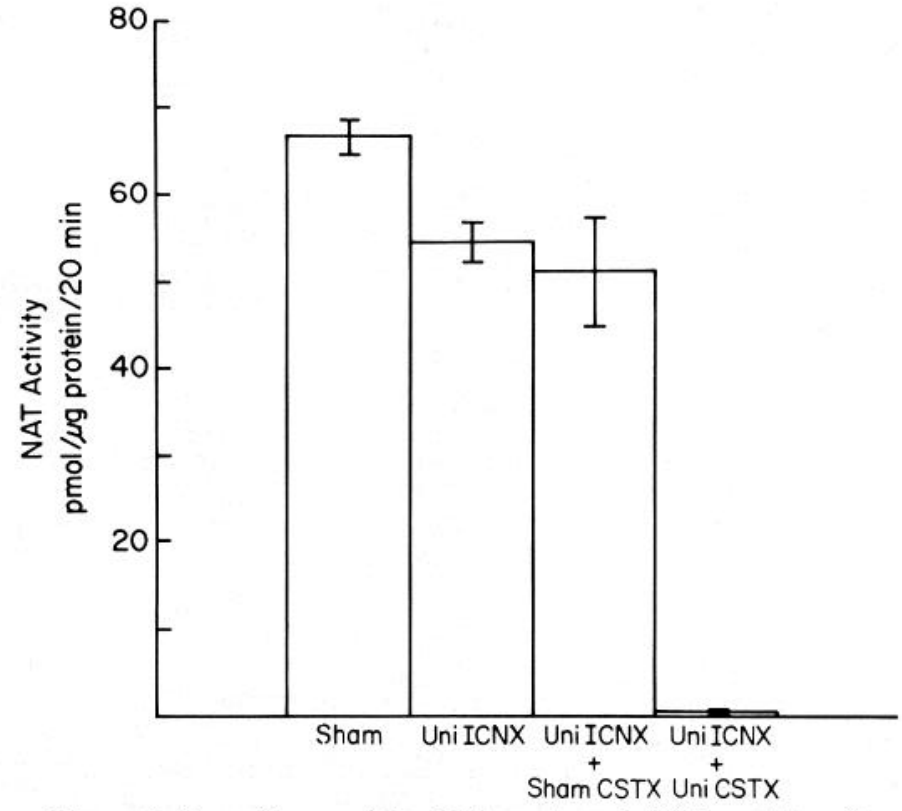

Figure 3. Dependence of the high nocturnal NAT activity after unilateral lesion of the ICN on sympathetic neurons on the contralateral side. Animals either were sham-operated or had their ICN cut on one side (UniICNX). One month later, some of the lesioned animals either were sham operated or had their contralateral CSTs cut (UniCSTX). Nocturnal NAT activity was measured $32 \mathrm{hr}$ after the second operation. Each data point represents the mean \pm SEM of 8 to 11 pineal glands.

NAT activity in unilaterally denervated pineal glands. In fact, NAT activity in these animals after unilateral stimulation was not significantly different from NAT activity in sham-operated animals after bilateral stimulation (Fig. 4).

Correlation of the recovery process with biochemical evidence of nerve terminal degeneration. As part of an attempt to determine the extent of degeneration of the sympathetic varicosities in the pineal gland $32 \mathrm{hr}$ after lesioning the ICN, the norepinephrine content of the gland was measured. In this experiment, NAT activity was assayed in the same pineal glands. Thirty-two hours after unilateral denervation, a time by which NAT activity had returned to normal, the norepinephrine content of the pineal gland was $42 \%$ of that found in control animals (Fig. 5). In bilaterally denervated pineal glands, the norepinephrine contènt was only $7 \%$ of control values.

The effect of unilateral denervation and unilateral decentralization on the ability of the pineal gland to take up catecholamines was examined by measuring the uptake of $\left[{ }^{3} \mathrm{H}\right]$ norepinephrine by whole glands in vitro. The uptake of norepinephrine by pineal glands from unoperated animals was linear with time for at least $20 \mathrm{~min}$, was temperature dependent, and was inhibitable by the drug desmethylimipramine. Lowering the temperature of the incubation medium from $37^{\circ} \mathrm{C}$ to $4^{\circ} \mathrm{C}$ decreased norepinephrine uptake by about $95 \%$. Addition of desmethylimipramine $\left(10^{-6} \mathrm{M}\right)$ decreased uptake by $90 \%$, and the $\mathrm{IC}_{50}$ for the effect of desmethylimipramine was about $10^{-8}$ M (Fig. 6). Prior lesioning of both ICNs produced a similar reduction in norepinephrine uptake, as did incubation with a high concentration of desmethylimipramine (Fig. 6). Therefore, the uptake of norepinephrine seen in bilaterally denervated pineal glands or in normal glands incubated with $10^{-5} \mathrm{M}$ desmethylimipramine was considered non-neuronal. In other experimental groups this value was subtracted from the total uptake to determine the specific neuronal uptake.

In the experiment shown in Figure $7,\left[{ }^{3} \mathrm{H}\right]$ norepinephrine uptake was measured 9,32 , and $80 \mathrm{hr}$ after unilateral dener-

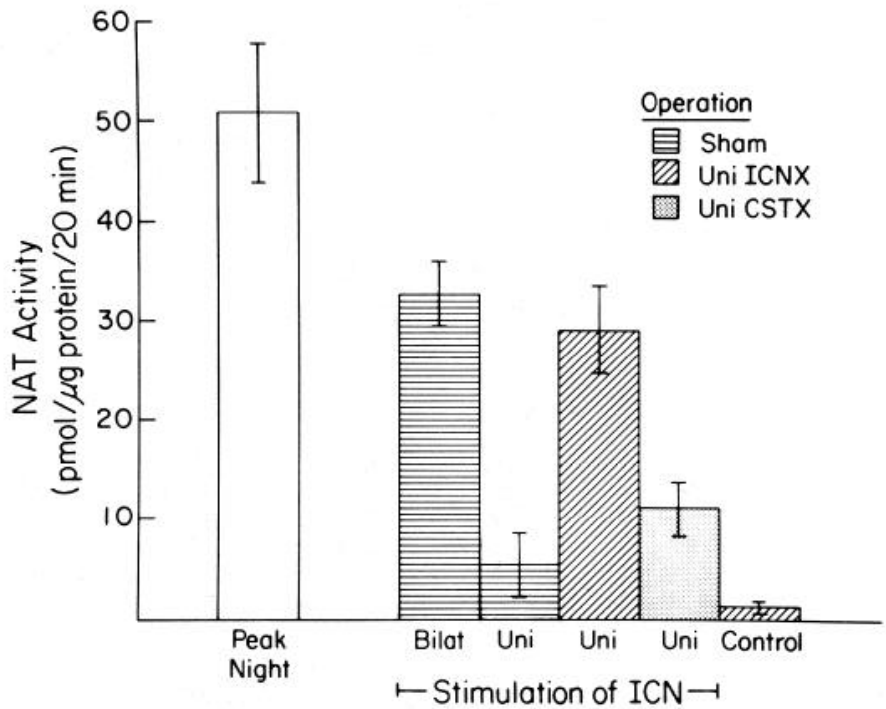

Figure 4. Effect of unilateral stimulation of the ICN on NAT activity in unilaterally denervated and unilaterally decentralized pineal glands. Animals were either sham-operated, or their ICN was cut on one side (Uni ICNX), or their CST was cut on one side (Uni CSTX). Two days later, the contralateral ICN was stimulated electrically at $5 \mathrm{~Hz}$ for $3 \mathrm{hr}$ during the daytime. Pineal glands were removed, frozen immediately after the stimulation was completed, and stored at $-80^{\circ} \mathrm{C}$ before enzyme assay. In one group of sham-operated animals the ICNs were stimulated bilaterally (Bilat), and in one group of animals whose ICNs had been cut unilaterally the contralateral ICN was exposed but not stimulated (Control). A group of unoperated animals was also included to allow the NAT activity in stimulated animals to be compared to the peak night-time levels of NAT activity in unoperated animals (Peak Night). Each group includes five to eight pineal glands. Due to the large number of animals in this experiment, it was impossible to include daytime unoperated controls and anesthetized but nonstimulated controls for all groups. However, a comparison of the NAT value for the nonstimulated, unilaterally denervated pineal glands reported here $(1.5 \pm 0.6$ $\mathrm{pmol} / \mu \mathrm{g}$ of protein $/ 20 \mathrm{~min}$ ) with the daytime unoperated value for this same group, which we have reported previously $(0.23 \pm 0.08$, Zigmond et al., 1981), suggests that there is a small increase in enzyme activity in this group due to handling, anesthesia, and exposure of the ICN. A similar small increase in NAT activity due to these procedures has been reported previously in animals 3 months after bilaterally crushing the ICN (Bowers et al., 1984a).
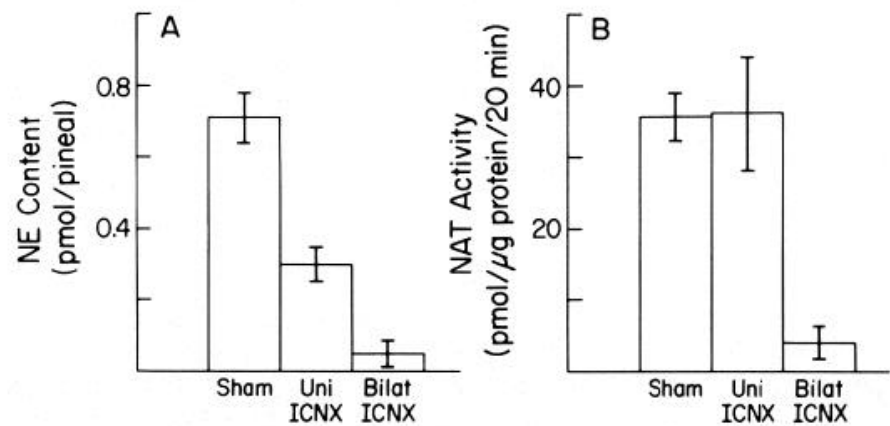

Figure 5. The effect of lesioning the ICN on the norepinephrine $(N E)$ content and nocturnal NAT activity in the pineal gland. Animals either were sham-operated or had their ICN cut unilaterally or bilaterally (Uni ICNX or Bilat ICNX) $32 \mathrm{hr}$ previously. Both the norepinephrine content and NAT activity of the pineal glands were determined 7 to $8 \mathrm{hr}$ into the dark period. Each bar represents the mean of 7 or 8 animals.

vation. At the earliest time point, there was no change in the uptake of this catecholamine compared to sham-operated controls; however, at $32 \mathrm{hr}$, total uptake was decreased by $42 \%$ and neuronal uptake by $47 \%$. Eighty hours after unilateral dener- 


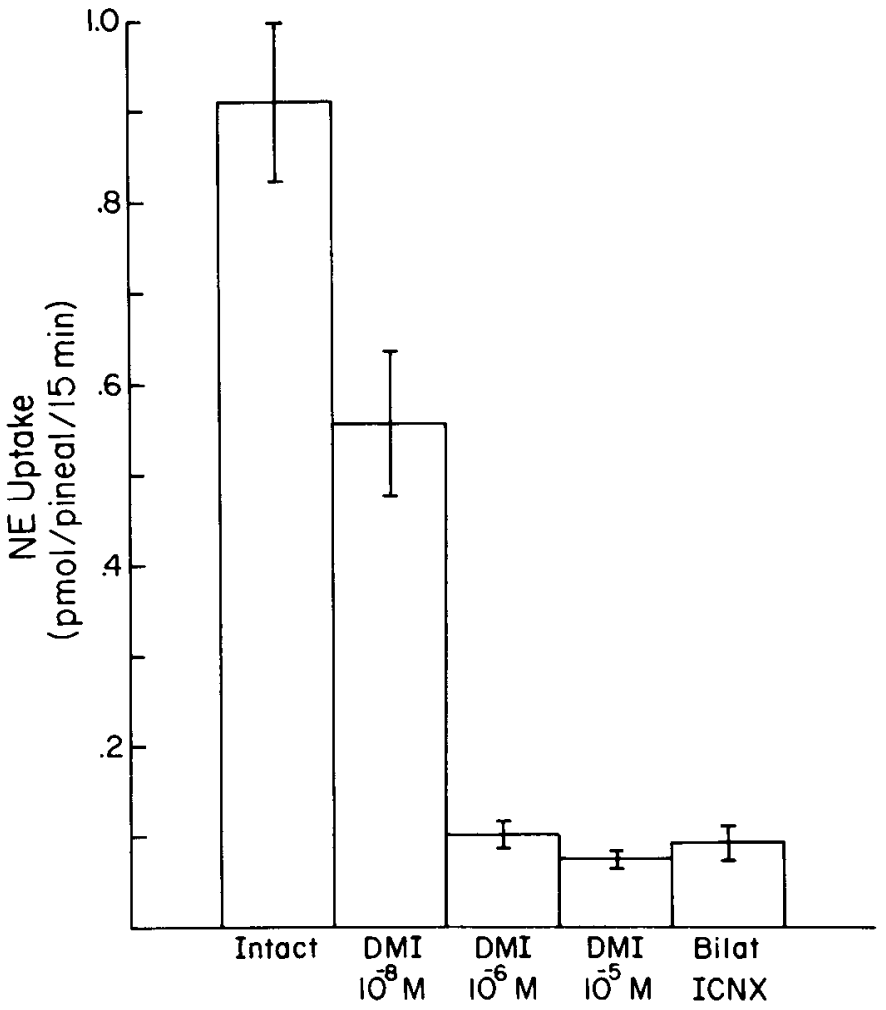

Figure 6. Norepinephrine $(N E)$ uptake in pineal glands in vitro. Pineal glands were incubated with $\left[{ }^{3} \mathrm{H}\right]$ norepinephrine $\left(1.3 \times 10^{-7} \mathrm{M}\right)$ with and without desmethylimipramine $(D M I)$ at the concentrations shown. In one group of animals, the ICNs were cut bilaterally 12 days before norepinephrine uptake was measured (Bilat ICNX). Each bar represents the mean \pm SEM of seven pineal glands. The uptake of norepinephrine was not significantly different in normal pineal glands treated with $10^{-6}$ or $10^{-5} \mathrm{M}$ desmethylimipramine or in bilaterally denervated glands.

vation, $\left[{ }^{3} \mathrm{H}\right]$ norepinephrine uptake had increased somewhat from the level seen at $32 \mathrm{hr}$ and was no longer significantly different from control values (Fig. 7). A number of similar experiments on the effects of unilateral denervation on neuronal norepinephrine uptake in the pineal gland was performed. The mean values obtained (expressed as a percentage of shamoperated controls) 9,32 , and $80 \mathrm{hr}$ after unilateral denervation were $89 \pm 6(N=21$ pineal glands), $60 \pm 5(N=35)$, and $72 \pm$ $5 \%(N=36)$. In contrast to the effects of denervation, neither unilateral nor bilateral decentralization significantly changed the uptake of norepinephrine by the pineal gland (data not shown).

\section{Restoration of normal pineal function after unilateral decentralization}

As noted above, animals do not appear to be capable of compensating for the lesion of one CST as evidenced by the persistent low level of NAT activity. To determine whether this lack of recovery is due to an inhibitory effect on pineal function produced by the decentralized neurons themselves, the ipsilateral ICN was cut in animals whose CST had been cut unilaterally 1 month earlier. Thirty-two hours later, nocturnal NAT activity was restored to normal in these doubly lesioned animals (Fig. 8). In contrast, unilaterally lesioned animals that were subsequently sham-operated showed no elevation in NAT activity (Fig. 8).

To examine one possible basis for the inhibitory effect of the decentralized neurons, animals were injected with the norepinephrine uptake blocker desmethylimipramine. Administration of this drug 7 and $2 \mathrm{hr}$ before nocturnal NAT activity was measured restored NAT activity to normal in animals whose

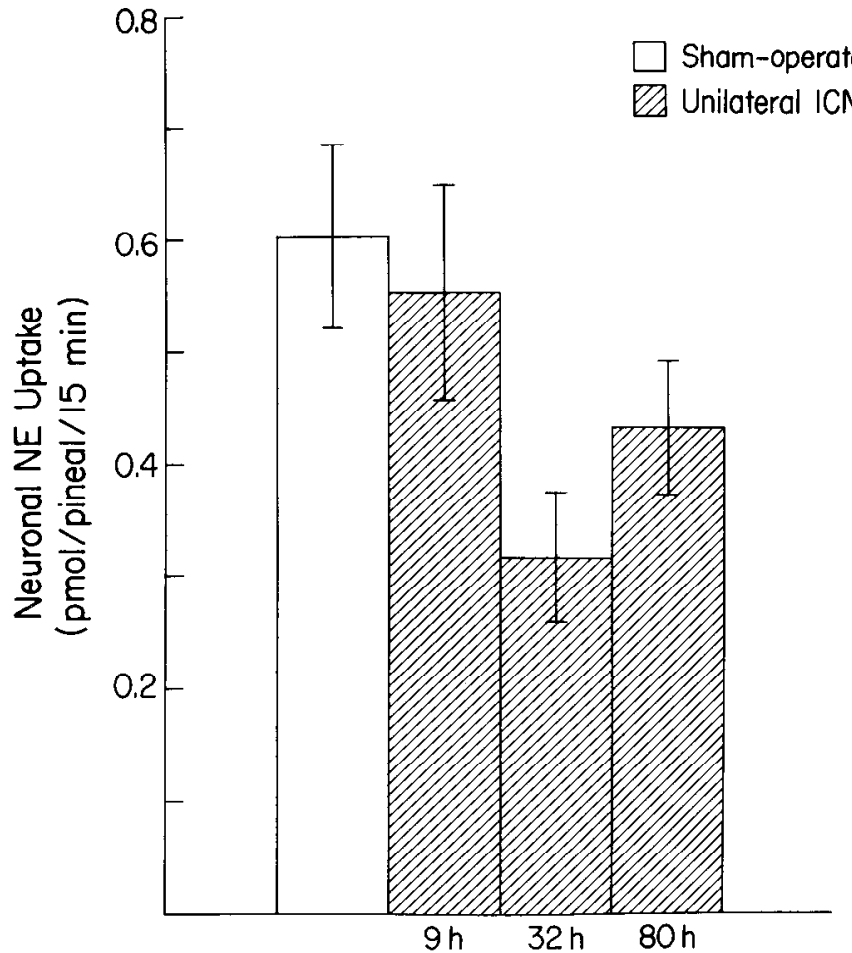

Figure 7. Norepinephrine $(N E)$ uptake in pineal glands following lesions of the ICN. Total norepinephrine uptake was measured in pineal glands of sham-operated animals; of animals whose ICN had been cut on one side 9,32 , and $80 \mathrm{hr}$ previously; and of animals whose ICNs had been cut on both sides 7 days previously. Specific neuronal uptake was determined by subtracting the uptake obtained in the bilaterally denervated group from the uptake obtained in each of the other four groups. The concentration of $\left[{ }^{3} \mathrm{H}\right]$ norepinephrine used was $1.2 \times 10^{-7} \mathrm{M}$. Each bar represents the mean \pm SEM of seven or eight pineal glands.

CST had been cut unilaterally $32 \mathrm{hr}$ previously (Fig. 9). Since NAT activity is also depressed in unilaterally denervated pineal glands $9 \mathrm{hr}$ after the lesion, the effect of desmethylimipramine was examined under these conditions. The uptake blocker was found to elevate NAT activity to normal values in these animals (Fig. 9). Although desmethylimipramine also increased NAT activity in animals whose CST had been cut bilaterally, the enzyme activity in these animals was only $35 \%$ of that found in vehicle-injected, sham-operated controls.

\section{Discussion}

Nine hours after the ICN was lesioned unilaterally, the nocturnal NAT activity in the pineal gland was decreased by about $75 \%$. However, during the second night $(32 \mathrm{hr}$ after the operation) and during subsequent nights (i.e., $80 \mathrm{hr}$ and 1 month after the operation), NAT activity was normal. In contrast, although nocturnal NAT activity was also decreased by $75 \%, 9 \mathrm{hr}$ after a unilateral lesion of the CST, it did not increase from this low level for up to 5 months after the operation. This time course indicates that the difference between the two types of operations is not simply that a slower process of recovery takes place after unilateral decentralization than after unilateral denervation. It also indicates that the recovery after unilateral denervation is not a transitory phenomenon. This demonstration is particularly important since it is known that, after lesioning sympathetic neurons, a brief stimulation of the denervated tissue may occur due to transmitter being released from degenerating varicosities (Langer, 1966; Lundberg, 1969). In the rat, "degeneration stimulation" of exophthalmus occurs approxiamtely $14 \mathrm{hr}$ after ganglionectomy and lasts for approx- 


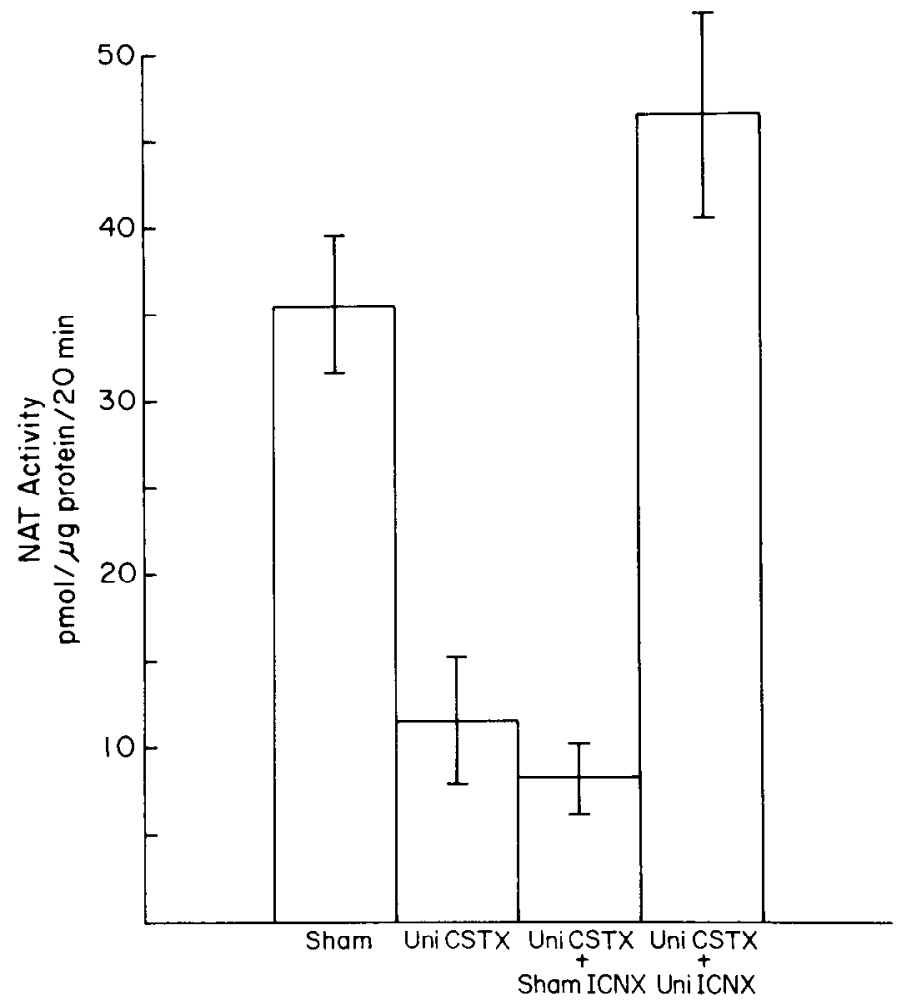

Figure 8. Effect of cutting the ipsilateral internal carotid nerve on the NAT activity of previously unilaterally decentralized pineal glands. Animals were sham-operated (Sham) or had one CST cut (Uni CSTX). One month later, two groups of lesioned animals either were shamoperated (Uni CSTX + Sham ICNX) or had their ipsilateral ICN cut (Uni CSTX + Uni ICNX). NAT activity was measured $32 \mathrm{hr}$ later, 7 to $8 \mathrm{hr}$ into the dark cycle. Each bar represents the mean $\pm \mathrm{SEM}$ of nine animals. The NAT activity in the doubly lesioned animals was 5.7 times higher than that in the Uni CSTX + Sham ICNX animals but not significantly different from that in the nonlesioned animals (Sham).

imately $12 \mathrm{hr}$ (Lundberg, 1966). Since NAT activity is normal in unilaterally denervated pineal glands from $32 \mathrm{hr}$ to $1 \mathrm{month}$ after the lesion is made, these levels of enzyme activity cannot simply be the direct result of norepinephrine leaking out of degenerating varicosities.

In contrast to the complete recovery which occurs in animals after unilateral denervation, an extremely small increase in NAT activity occurs after bilateral denervation (Zigmond et al., 1981). Furthermore, the increase in unilaterally denervated pineal glands can be blocked completely by cutting the contralateral CST. Thus, the ability of animals whose ICN has been cut unilaterally to re-establish and to maintain normal nocturnal NAT activity is completely dependent on the integrity of the intact contralateral CST. Our results also demonstrate that, unlike in certain neural systems, where sequential partial lesions have been shown to produce less damage than a single large lesion (Stein, 1974), in this system sequential lesioning of the two sympathetic inputs to the pineal gland results in the same deficit as concurrent lesioning of both inputs. These data suggest that in this system no new neural pathway or humoral influence takes over the function of the lesioned neurons.

The time course of the recovery of NAT activity after the ICN is cut unilaterally follows the time course of the degeneration of the varicosities of the lesioned adrenergic neurons. Biochemical evidence for this conclusion comes from the present findings that the norepinephrine content of the pineal gland and the ability of the gland to take up norepinephrine decreased by about $50 \%$ within $32 \mathrm{hr}$ after the lesion. On the other hand,

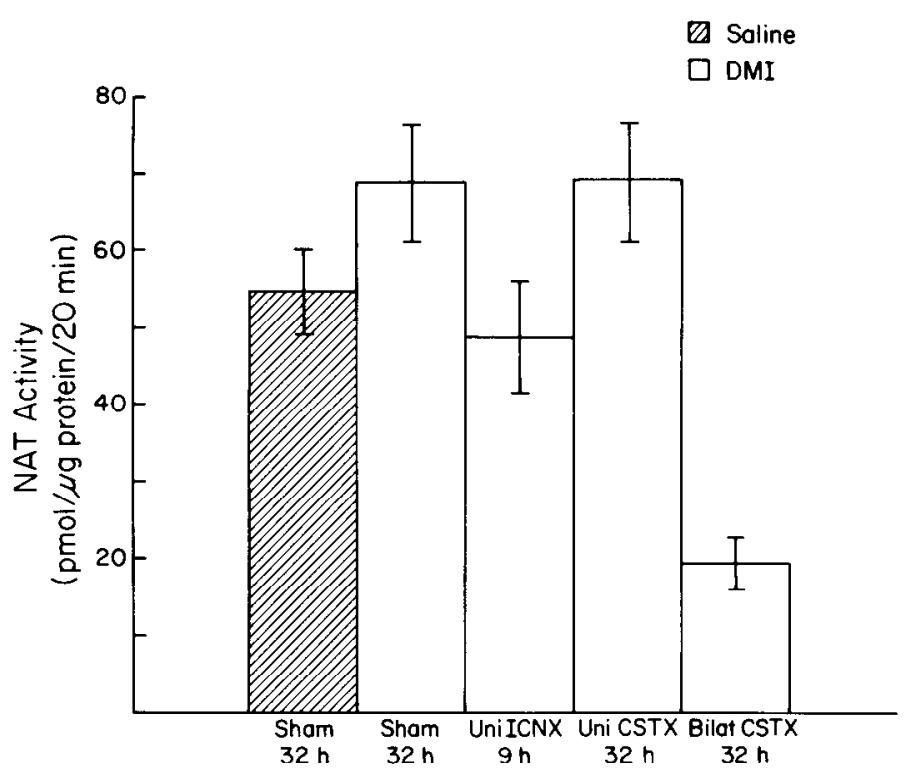

Figure 9. Effect of systemic administration of desmethylimipramine on NAT activity in unilaterally denervated and unilaterally decentralized pineal glands. Desmethylimipramine hydrochloride $(D M I)$ was injected into animals $32 \mathrm{hr}$ after a sham-operation, $9 \mathrm{hr}$ after unilateral denervation (Uni ICNX), $32 \mathrm{hr}$ after unilateral decentralization (Uni CSTX), or $32 \mathrm{hr}$ after bilateral decentralization (Bilul CSTX). One group of sham-operated animals received the saline vehicle alone. The drug injections were given $7 \mathrm{hr}(20 \mathrm{mg} / \mathrm{kg})$ and $2 \mathrm{hr}(10 \mathrm{mg} / \mathrm{kg})$ before removal of the pineal gland for NAT assay. NAT was measured 7 to 8 hr into the dark cycle. Each bar represents the mean \pm SEM of eight animals. The only group which differed significantly in NAT activity from that in pineal glands of vehicle-injected control animals was that of bilaterally decentralized pineal glands from desmethylimipraminetreated animals. In a control experiment (see "Materials and Methods"), it was shown that the regimen of desmethylimipramine administration used here inhibited by $80 \%$ the uptake of a trace amount of norepinephrine injected systemically.

$9 \mathrm{hr}$ after the lesion (a time at which NAT activity is depressed), norepinephrine uptake is similar to that seen in sham-operated controls. Similarly, Morgan and Hansen (1978) previously reported no change in norepinephrine content of the pineal gland $8 \mathrm{hr}$ after bilateral superior cervical ganglionectomy, although they found an almost total depletion of the transmitter by 24 hr. Anatomical evidence for the correlation between the recovery of function and neuronal degeneration is provided by an electron microscopic study showing signs of degeneration of pineal varicosities at $24 \mathrm{hr}$, although not at $8 \mathrm{hr}$, after superior cervical ganglionectomy (Morgan and Hansen, 1978; King and Doherty, 1982).

In considering possible mechanisms to account for the recovery of pineal function after partial denervation, certain characteristics of the recovery process should be kept in mind. First of all, the recovery is remarkably rapid, occurring within $32 \mathrm{hr}$ after the lesion. Second, the recovery represents a long-lasting (and probably permanent) change. Third, the recovery occurs after unilateral denervation but not after unilateral decentralization.

Three mechanisms are commonly cited to account for recovery of function following neural damage: regenerative sprouting, collateral sprouting, and increased postjunctional sensitivity. The uptake data reported here suggest that neither regenerative nor collateral sprouting are likely to account for the rapid recovery of pineal function. This interpretation of the data is based on the assumption that an increase in the number of adrenergic varicosities in a tissue is accompanied by an increase in the number of norepinephrine uptake sites, an assumption supported by previous research (e.g., Olson and Malmfors, 
1970). The fact that, at 12 days after bilaterally lesioning the ICN, the uptake of norepinephrine is indistinguishable from that seen in intact pineal glands exposed to a high concentration of the neuronal uptake blocker desmethylimipramine $\left(10^{-5}\right.$ M) indicates that little, if any, reinnervation of the pineal gland occurs over this time period. Similarly, the fact that norepinephrine uptake is decreased by about $50 \%, 32 \mathrm{hr}$ after unilateral denervation, suggests that little, if any, collateral sprouting has occurred within this time. An increase in norepinephrine uptake does appear to occur between 32 and $80 \mathrm{hr}$ after a unilateral lesion, perhaps reflecting collateral sprouting. However, although this change deserves further study, it should be noted that it occurs after NAT activity has returned to normal values.

Increased sensitivity of pinealocytes to $\beta$-adrenergic stimulation is known to occur rapidly (i.e., within $24 \mathrm{hr}$ ) after bilateral denervation of the pineal gland (Deguchi and Axelrod, $1972 \mathrm{c})$. Although it has been reported that the development of postjunctional supersensitivity is slower after bilateral decentralization than after bilateral denervation, the extent of the supersensitivity developed was found to be similar by 14 days after both types of lesions (Deguchi and Axelrod, 1972c, 1973b). Preliminary results in our laboratory suggest that, paradoxically, whereas postjunctional supersensitivity is seen in the pineal gland 2 days after unilateral decentralization, it is not seen after unilateral denervation (R. E. Zigmond and C. Baldwin, unpublished results). These latter data suggest that postjunctional supersensitivity may develop as a consequence of a lack of recovery of normal adrenergic stimulation of the pineal gland (e.g., after unilateral decentralization) rather than being the cause of a recovery of normal stimulation (e.g., after unilateral denervation).

A fourth hypothesis which could account for the recovery of pineal function is that, by some mechanism, unilateral denervation triggers an increase in impulse activity in the contralateral intact sympathetic neurons. Although, theoretically, such an increase in firing could occur after unilateral denervation

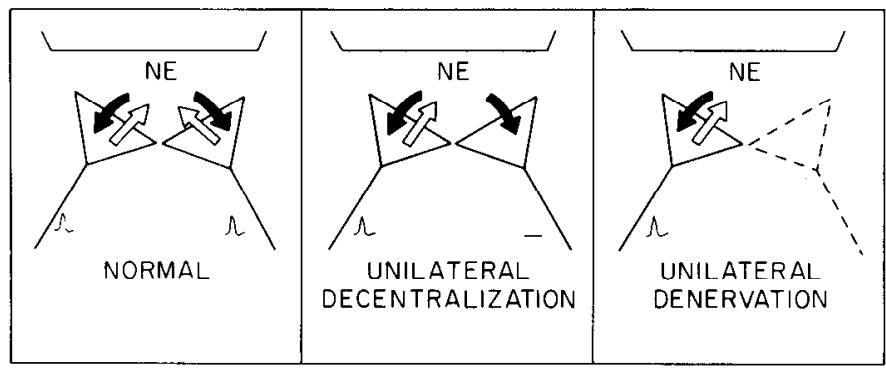

Figure 10. A model to account for the recovery of pineal NAT activity after unilateral denervation but not after unilateral decentralization of the pineal gland. 'Two sympathetic nerves, one from the left and one from the right superior cervical ganglion, are pictured innervating the same pinealocyte. In the normal animal, both neurons are electrophysiologically active and are releasing norepinephrine $(N E)$ as shown by the white arrows. In addition, both neurons take up norepinephrine as shown by the black arrows. The situation in unilaterally decentralized pineal glands is depicted in the middle panel. In this diagram a neuron from one superior cervical ganglion is shown as electrophysiologically inactive and therefore as not releasing norepincphrine. However, the uptake capacity of this neuron is intact. Therefore, the net effect of these electrophysiologically inactive neurons is to inhibit the postsynaptic effectiveness of the aclive sympathetic neurons from the contralateral ganglion. In the right panel, the situation in the unilaterally denervated pineal gland is shown. Sometime between 9 and $32 \mathrm{hr}$ after cutting one ICN, the terminals of these nerves degenerate, thus decreasing the number of varicosities taking up norepinephrine. The loss of these norepinephrine uptake sites increases the postsynaptic effectiveness of the neurons from the contralateral intact ganglion. and not after unilateral decentralization, it is not obvious what signal would trigger such a selective effect. Furthermore, if the firing rate of ICN fibers on the intact side were the only difference between animals whose pineal glands had been unilaterally denervated and those whose glands had been unilaterally decentralized, then these animals would not respond differently to unilateral electrical stimulation of the ICN. However, unilateral stimulation at $5 \mathrm{~Hz}$ is much more effective in increasing pineal NAT activity after unilateral denervation than after either unilateral decentralization or sham-operation. In fact, unilateral stimulation of unilaterally denervated pineal glands is as effective as bilateral stimulation of control glands. These data suggest that no increase in firing rate is necessary to account for the recovery of NAT activity in unilaterally denervated pineal glands.

One clear difference between pineal glands $32 \mathrm{hr}$ after unilaterally cutting the ICN or unilaterally cutting the CST is in their ability to take up norepinephrine. Unlike unilaterally denervated pineal glands, unilaterally decentralized glands maintain their ability to take up this sympathetic neurotransmitter. We hypothesize that it is this difference which accounts for the rapid recovery of pineal function. The mechanism we propose is diagrammed in Figure 10. The main features of this model are: (1) that varicosities can take up norepinephrine released by other varicosities, (2) that neurons whose cell bodies are in each of the superior cervical ganglia have varicosities in the pineal gland close enough to each other to participate in this "heteroneuronal uptake," and (3) that the ability of a neuron to take up the transmitter released by another neuron reduces the effectiveness of the second neuron in stimulating its effector cells. Based on these ideas, the following sequence of events is proposed to account for our results. Nine hours after both unilateral denervation and unilateral decentralization, the amount of norepinephrine released in the pineal gland would be expected to decrease (probably by about $50 \%$ ), since half of the neurons innervating the gland would be electrophysiologically "silent." However, the uptake capacity of these silent neurons would be intact and would inhibit the efficacy of the remaining (active) neurons to stimulate the pinealocytes. During the next $24 \mathrm{hr}$ the varicosities of the axotomized neurons would degenerate and their uptake capacity would be lost, thus relieving the active neurons from inhibition. This would increase the stimulatory capacity of these neurons and would lead to a permanent restoration of pineal function. Since the uptake capacity of the decentralized neurons would not be altered, the NAT activity in decentralized animals would remain low.

Studies on the topography of the sympathetic innervation of the pineal gland provide support for this model. We have shown, by anterograde filling of axons with horseradish peroxidase, that fibers from one nervus conarii (the bundle of sympathetic fibers which innervates the pineal gland) spread out over the entire surface of the pineal gland rather than being restricted to one half of the gland (Bowers et al., 1984b). Furthermore, when these axons were followed in serial sections, groups of axons from one nervus conarii were seen to merge with groups of axons from the contralateral nervus conarii (Bowers et al., 1984b). Recently, electron microscopic evidence has been presented that, $24 \mathrm{hr}$ after unilateral ganglionectomy, sympathetic varicosities decrease by about $50 \%$ in both ipsilateral and contralateral halves of the pineal gland (King et al., 1983). It has also been noted that sympathetic varicosities in the pineal gland tend to occur in clusters and that individual varicosities rarely make close synaptic contacts with pinealocytes (Arstila, 1967; Moore, 1978; Hess, 1981; King et al., 1983). This arrangement might allow transmitter released by one varicosity to be taken up by another varicosity, and this uptake mechanism could influence the ability of the first varicosity to stimulate 
postjunctional receptors. (Whether a single cluster of varicosities contains elements from neurons in both superior cervical ganglia remains to be demonstrated.)

If the uptake of norepinephrine by electrophysiologically "silent neurons" is the basis for the lack of recovery of function both in unilaterally denervated pineal glands $9 \mathrm{hr}$ after the lesion and in unilaterally decentralized glands at all times after lesioning, the administration of an antagonist of norepinephrine uptake should restore function to normal in both cases. Furthermore, the model suggests that normal function could be restored in unilaterally decentralized pineal glands by a second operation in which the ipsilateral ICN was cut. All of these predictions have been shown to be true.

Our model, then, postulates an inhibitory interaction between neurons based on transmitter uptake. A related hypothesis, which is difficult to distinguish experimentally from this hypothesis, is one in which neurons would inhibit each other by modulating the amount of transmitter each released. The difficulty of postulating a mechanism involving regulation of transmitter release to explain the recovery of pineal function after unilateral denervation, but not after unilateral decentralization, is that it implies that electrophysiologically inactive neurons are releasing enough of such an inhibitory substance to effectively inhibit norepinephrine release from the remaining (active) neurons. If, for example, the inhibitory substance were norepinephrine itself one might envision that in normal neurons the norepinephrine released would stimulate both postsynaptic $\beta$-adrenergic receptors and presynaptic $\alpha$-adrenergic receptors, perhaps inhibiting the release of norepinephrine by varicosities of other neurons via the latter mechanism. However, much less norepinephrine would be released by decentralized neurons and, thus, any inhibitory effects would be expected to be smaller. The extremely low NAT activity seen in bilaterally decentralized pineal glands (in spite of the development of postjunctional supersensitivity) indicates that little norepinephrine is being released. Similarly, even if an inhibitory substance other than norepinephrine is postulated, it would also have to be released by decentralized neurons. Thus, although theoretically possible, the idea that the loss of presynaptic inhibition of transmitter release accounts for the recovery seems to us less plausible than the hypothesis presented above. However, it should be noted that the two hypotheses are similar in many ways, particularly in postulating an inhibitory influence exerted by electrophysiologically inactive neurons.

Phenomena analogous to those described in this study may well occur following neural damage in the central nervous system. It has been shown that many neurotransmitters in the brain (e.g., norepinephrine, dopamine, serotonin, GABA, and glycine) can be actively taken up by specific transport processes in nerve terminals (Iversen, 1975; Iversen et al., 1975). Thus, a mechanism of recovery based on loss of uptake sites may be widely applicable. Furthermore, in certain instances the cause of the loss of function after brain damage may be due to a persistent inhibitory influence of denervated neurons. Our findings that function can be restored to normal in unilaterally decentralized pineal glands by administration of an antagonist of norepinephrine uptake or by a surgical lesion of the decentralized neurons may have implications for treatment in certain instances of permanent central nervous system damage.

Recently, a suggestion has been made, based on changes in desmethylimipramine binding sites in response to certain pharmacological manipulations, that the uptake capacity of a neuron may be alterable (Lee et al., 1983). If fluctuations in the uptake capacity of neurons occur under normal conditions, our data suggest that such changes might influence the synaptic efficacy of nearby neurons that use the same neurotransmitter. Thus, regulation of heteroneuronal uptake may be a mechanism of synaptic plasticity in intact tissues.

\section{References}

Arstila, A. U. (1967) Electron microscopic studies on the structure and histochemistry of the pineal gland of the rat. Neuroendocrinology (Suppl.) 2: 1-101.

Bowers, C. W., and R. E. Zigmond (1980) Electrical stimulation of the cervical sympathetic trunks mimics the effects of darkness on the activity of serotonin: $N$-acetyltransferase in the rat pineal. Brain Res. 185: 435-440.

Bowers, C. W., and R. E. Zigmond (1982) The influence of the frequency and pattern of sympathetic nerve activily on serotonin $\mathrm{N}$-acetyltransferase in the rat pineal gland. J. Physiol. (Lond.) 330: 279-296.

Bowers, C. W., C. Baldwin, and R. E. Zigmond (1984a) Sympathetic reinnervation of the pineal gland after postganglionic nerve lesion does not restore normal pineal function. J. Neurosci. 4: 2010-2015.

Bowers, C. W., L. Dahm, and R. E. Zigmond (1984b) The number and distribution of sympathetic neurons that innervate the rat pineal gland. Neuroscience 13: 87-96.

Deguchi, T., and J. Axelrod (1972a) Sensitive assay for serotonin $N$ acetyltransferase activity in rat pineal. Anal. Biochem. 50: 174-179.

Deguchi, T., and J. Axelrod (1972b) Control of circadian change of serotonin $N$-acetyltransferase activity in the pineal organ by the $\beta$ adrenergic receptor. Proc. Natl. Acad. Sci. U. S. A. 69: 2547-2550.

Deguchi, T., and J. Axelrod (1972c) Induction and superinduction of serotonin $\mathrm{N}$-acetyltransferase by adrenergic drugs and denervation in rat pineal organ. Proc. Natl. Acad. Sci. U. S. A. 69: 2208-2211.

Deguchi, T., and J. Axelrod (1973a) Superinduction of serotonin $N$ acetyltransferase and supersensitivity of adenyl cyclase to catecholamines in denervated pineal gland. Mol. Pharmacol. 9: 612-618.

Deguchi, T., and J. Axelrod (1973b) Supersensitivity and subsensitivity of the $\beta$-adrenergic receptor in pineal gland regulated by catecholamine transmitter. Proc. Natl. Acad. Sci. U. S. A. 70: 2411-2414.

Erny, R. E., M. W. Berezo, and R. L. Perlman (1981) Activation of tyrosine 3-monooxygenase in pheochromocytoma cells by adenosine. J. Biol. Chem. 256: 1335-1339.

Hess, A. (1981) Localization of noradrenaline and serotonin in nerves in the pineal glands of rats and guinea-pigs studied by glyoxylic acid histofluorescence and electron microscopy. Histochem. J. 13: 425434.

Holz, R. W., T. Deguchi, and J. Axelrod (1974) Stimulation of serotonin $\mathrm{N}$-acetyltransferase in pineal organ culture by drugs. J. Neurochem. 22: 205-209.

Iversen, L. L. (1975) Uptake processes for biogenic amines. In Handbook of Psychopharmacology, L. L. Iversen, S. D. Iversen, and S. H. Snyder, eds., Vol. 3, pp. 381-442, Plenum Press, New York.

Iversen, L. L., F. Dick, J. S. Kelly, and F. Schon (1975) Uptake and localization of transmitter amino acids in the nervous system. In Metabolic Compartmentation and Neurotransmission, S. Berl. D. D. Clarke, and D. Schneider, eds., pp. 65-89, Plenum Press, New York.

Kappers, J. A. (1960) The development, topographical relations and innervation of the epiphysis cerebri in the albino rat. Z. Zellforsch. 52: 163-215.

Keller, R., A. Oke, I. Mefford, and R. N. Adams (1976) Liquid chromatographic analysis of catecholamines. Routine assay for regional brain mapping. Life Sci. 19:995-1004.

King, T. S., and W. J. Dougherty (1982) Effect of denervation on "synaptic" ribbon population in the rat pineal gland. J. Neurocytol. 11: $19-28$.

King, T. S., M. Karasek, R. W. Steger, J. T. Hansen, and R. J. Reiter (1983) Effect of acute or chronic unilateral superior cervical ganglionectomy on the adrenergic innervation of rat pineal gland. In Developing and Regenerating Vertebrate Nervous Systems, P. W. Coates, R. R. Markwald, and A. E. Kenny, eds., pp. 223-230, Alan R. Liss, Inc., New York.

Klein, D. C., J. L. Weller, and R. Y. Moore (1971) Melatonin metabolism: Neural regulation of pineal serotonin:acetylcoenzyme A $N$ acetyltransferase activity. Proc. Natl. Acad. Sci. U. S. A. 68: 31073110.

Langer, S. Z. (1966) The degeneration contraction of the niclitating membrane in the unanesthetized cat. J. Pharmacol. Exp. Ther. 151: 66-72.

Lee, C. M., J. A. Javitch, and S. H. Snyder (1983) Recognition sites for norepinephrine uptake: Regulation by neurotransmitter. Science 220 : 626-629.

Lowry, O. H., N. J. Rosebrough, A. L. Farr, and R. L. Randall (1951) 
Protein measurement with the Folin phenol reagent. J. Biol. Chem. 193: 265-275.

Lundberg, D. (1969) Adrenergic neuron blockers and transmitter release after sympathetic denervation studied in the conscious rat. Acta Physiol. Scand. 75: 415-426.

Lynch, H. J., J. P. Eng, and R. J. Wurtman (1973) Control of pineal indole biosynthesis by changes in sympathetic tone caused by factors other than environmental lighting. Proc. Natl. Acad. Sci. U. S. A. 70: 1704-1707.

Lynch, H. J., M. Ho, and R. J. Wurtman (1977) The adrenal medulla may mediate the increase in pineal melatonin synthesis induced by stress, but not that caused by exposure to darkness. J. Neural Transm. 40: 87-97.

Moore, R. Y. (1978) The innervation of the mammalian pineal gland. In The Pineal Gland and Reproduction, R. J. Reiter, ed., pp. 1-29, S. Karger AG, Basel.

Morgan, W. W., and J. T. Hansen (1978) Time course of the disappearance of pineal noradrenaline following superior cervical ganglionectomy. Exp. Brain Res. 32: 429-434.

Nagatsu, T., M. Levitt, and S. Udenfriend (1964) Tyrosine hydroxylase. The initial step in norepinephrine biosynthesis. J. Biol. Chem. 239: 2910-2917.
Olson, L., and T. Malmfors (1970) Growth characteristics of adrenergic nerve in the adult rat. Acta Physiol. Scand. Suppl. 348: 1111.

Owman, C. (1964) Sympathetic nerves probably storing two types of monoamines in the rat pineal gland. Int. J. Neuropharmacol. 2: 105112.

Parfitt, A. G., and D. C. Klein (1976) Sympathetic nerve endings in the pineal gland protect against acute stress-induced increase in $\mathrm{N}$ acetyltransferase (EC 2.3.1.5) activity. Endocrinology 99: 840-851.

Stein, D. G. (1974) Some variables influencing recovery of function after central nervous system lesions in the rat. In Plasticity and Recovery of Funtion in the Cenlral Nervous System, D. G. Stein, J. J. Rosen, and N. Butters, eds. pp. 373-427, Academic Press, Inc., New York.

Volkman, P. H., and A. Heller (1971) Pineal $N$-acetyltransferase activity: Effect of sympathetic stimulation. Science 173: 839-840.

Wurtman, R. J., J. Axelrod, and D. E. Kelly (1968) The Pineal, Academic Press, Inc., New York.

Zigmond, R. E., and A. Chalazonitis (1979) Long-term effects of preganglionic nerve stimulation on tyrosine hydroxylase activity in the rat superior cervical ganglion. Brain Res. 164: 137-152.

Zigmond, R. E., C. Baldwin, and C. W. Bowers (1981) Rapid recovery of function after partial denervation of the rat pineal gland suggests a novel mechanism for neural plasticity. Proc. Natl. Acad. Sci. U. S. A. $78: 3959-3963$. 